\title{
Examining the Relationship of Organizational Citizenship Behavior with Organizational Commitment and Equity Perception of Secondary School Administrators
}

\author{
Abdul Wahab Pourgaz ${ }^{1}$, Abdul Gader Naruei ${ }^{2}$, Hossein Jenaabadi ${ }^{1}$ \\ ${ }^{1}$ Faculty of Education, University of Sistan and Baluchestan, Zahedan, Iran \\ ${ }^{2}$ Educational Administration, University of Sistan and Baluchestan, Zahedan, Iran \\ Email: w.pourghaz@ped.usb.ac.ir
}

Received 27 November 2014; accepted 28 February 2015; published 27 May 2015

Copyright (C) 2015 by authors and Scientific Research Publishing Inc.

This work is licensed under the Creative Commons Attribution International License (CC BY). http://creativecommons.org/licenses/by/4.0/

\section{(c) (i) Open Access}

\section{Abstract}

The purpose of this study was to examine the relationship between organizational citizenship behavior with organizational commitment and equity perception of secondary school administrators in Zahedan. The descriptive-correlational method was applied. The population of the study included all secondary school administrators in Zahedan in 2013-2014 academic year $(\mathrm{N}=92)$. Using the sample size formula, 78 administrators were selected as respondents. Data collection instruments included Podsakoff's Organizational Citizenship Behavior Inventory (2000), Strone's Equity Perception Inventory (1996) and Steers and Porter's Organizational Commitment Questionnaire (1998). The content validity of the questionnaires was checked and their reliability was estimated using Cronbach's alpha coefficient which was $0.93,0.83$ and 0.72 , respectively. To investigate the research questions, Pearson correlation coefficient and stepwise regression analysis were used. Based on the findings of the research, there was a significant positive correlation between organizational citizenship behavior and both organizational commitment and equity perception of secondary school administrators in Zahedan. Considering the components of organizational citizenship behavior, there was a significant positive relationship between altruism and conscientiousness and equity perception, and between conscientiousness, sportsmanship, civic virtue and respect and organizational commitment. Moreover, there was a significant negative correlation between equity perception and organizational commitment. With regard to the components of organizational citizenship behavior, conscientiousness could predict equity perception 
and tribute could predict organizational commitment.

Keywords

Organizational Citizenship Behavior, Organizational Commitment, Equity Perception

\section{Introduction}

Human resource is considered as one of the most valuable organizational capitals and rarest source in the knowledge-based economy. This worthwhile capital has outdistanced other organizational capitals in terms of importance due to its great effect on organizational effectiveness. Accordingly, nowadays, organizations and managers apply various methods and strategies to recruit most skillful human forces. One of the worthwhile properties of human forces highly regarded is Organizational Citizenship Behavior (henceforth referred to as OCB) (Belcourt, Bohlander, \& Snell, 2008). Although the term was first proposed by Chester Barnard, Katz and Kahn, it was first used by Bittman and Organ (1983) investigating the relationship between job satisfaction and performance (Hossam, 2008). In the Organ's first definition of OCB, despite no compulsory burden from the organization to perform a certain behavior, if the behavior is performed, interests occur to the organization. According to Organ, OCB is a behavior that is voluntarily performed based on desire and determination and is not directly and clearly appreciated through formal organizational reward system; however, overall, it enhances effectiveness performance of the organization (Bolino \& Turnley, 2003).

OCB is a behavior which is based on the personal discretion apart from the employee's job requirements, yet increasing organizational effectiveness in order to satisfy the interests of the beneficiaries. In fact, OCB, with a set of voluntary and informal behavior, leads to effective improvements of organizational responsibilities and roles (Appelbaum et al., 2004). Yoon (2009) introduced OCB as a function which supported the psychological and social environment in which the occupational function took place (Awwad \& Agti, 2011). In addition, OCB implies fundamental cooperation and movements which are not directly mentioned in the formal definition of a job (Korkmaz \& Arpaci, 2009).

OCB identifies the type of responsibilities and behaviors that employees assume or represent, yet such responsibilities and behaviors are often ignored by the organizational system. This behavior's, despite being fully measured in the traditional evaluation of job performance or even sometimes being overlooked, very existence is effective in improving the organizational effectiveness. Finkelstein and Penner defined OCB as work activities that were surplus to requirements of the official duty and helped organization act effectively. According to them, OCB is proposed as a social organizational behavior (Finkelstein \& Penner, 2004). In another definition, OCB is defined as a behavior that is beyond the defined job roles which is not directly and openly recognized by the formal reward system, while, in general, this behavior enhances the effective performance of the organization (Chiu \& Chen, 2005). Given the above definitions, it can be concluded that OCB is a positive behavior which is voluntarily exhibited by people, is not under obligation of formal job requirements, and is not associated with rewards through the formal system of the organization. It is performed in order to help the organization toward more productivity. In Organ's viewpoint, dimensions of OCB include:

1) Altruism: Helping behaviors that are performed by an individual to aid certain staff regarding certain organizational responsibilities and issues. In other words, helping other members of the organization with pertinent difficulties and tasks, e.g. employees who help newcomers or the low-skilled.

2) Conscientiousness: Behaviors conducted by the employee to optimally perform the organizational responsibilities beyond the determined job requirement or what he/she expects. In other words, it refers to optional behavior surpassing the minimum requirements of the role, e.g. the individual who unusually works overtime or the employee that does not rest much. People who exhibit progressive citizenship behavior continue working in the worst conditions, even in the case of illness and inability, representing their high conscientiousness. Such behavior enhances trust among employees (Ramin Mehr, Hadizadeh Moghaddam, \& Ahmadi, 2009).

3) Sportsmanship: Tolerance and forgiveness in organizational undesirable conditions without complaining and discomfort (Castro, Armario, \& Ruiz, 2004). In other words, the emphasis on the positive aspects of the organization rather than its negative aspects is called sportsmanship. Therefore, sportsmanship is defined as the 
ability of employees to adapt to hardship and inconvenient workplace without verbal or formal protest or complaint (Ayoubi Rad, 2009).

4) Civic virtue: Active responsibilities and roles that staff as organizational citizens in the political life of the organization assume. In addition, it is concerned with the tendency to participation and accountability in the organizational life representing an appropriate image of the organization. Accordingly, a good organizational citizen should not only be aware of the issues of the day, but should comment on them and actively participate in the solution (Wang \& Tasi, 2010).

5) Tribute: Thinking of the effects of actions on others. Tribute refers to staff trying to prevent tension and work problems in the relationships with others. Tribute includes all foresights to prevent problems with other employees. Respect to the rights and privileges of others, consultation with those who may be affected by a decision or action, and informing others before any major action can represent tribute (Castro et al., 2004).

One of the motivation theories discussing equilibrium is the equity theory. The equity theory, introduced by Stacy Adams, is based on the fact that individuals want to be treated with justice. According to this theory, the equity perception (henceforth referred to as EP) is an employee's perception of his/her outcomes/inputs being lower, equal to or great than a reference outcome/input. In other words, equity is a comparison that one always draws which is secured when the ratio of one's input and outcome compared with a comparable resource strikes the equilibrium state (Saatchi, 2008). The process of EP of individuals to each other in the workplace works on the basis of input to output. Input encompasses the person's educational level, experience, diligence and loyalty to the organization and output refers to the salary, wages, social relations, recognition, reputation and intrinsic rewards. Employees first assess their organization's behavior toward themselves in comparison with others. Thus, they perceive the sense of satisfaction or dissatisfaction with the organization (Bjork, Samdal, Hansen, \& Torstad, 2007). On the other hand, one of the key concepts used in the organizations is organizational commitment (henceforth referred to as OC) that reflects individuals' attitude toward organizational values and goals and represents a force that requires an individual to stay in the organization and affectionately perform tasks to realize organizational goals (Jafari, Sadeghi, \& Khodayari Zarnaq, 2011). Jesse Erdheim (2006) defines OC as a mental state that determines the type of the employee's relationship with the organization. This relationship contains results for the employee that determine the continuance of the employee's membership in the organization and is able to provide managers with useful information on planning, organizing, and increasing efficiency. The presence of committed employees enhances the organization's social reputation and paves the way for its development and progress (Baker, Hunt, \& Andrews, 2006).

\section{Research Background}

The relationship between OCB and OC and the correlation between EP and OC are widely researched. To learn more about such relationships, some of the results of the recently conducted studies in this context will be discussed; however, regarding the relationship between the variable of OCB and EP of employees, no distinct research study has been conducted.

The results of Parnell \& Crandall (2003) suggested that there was a significant relationship between OCB and OC. Bogler \& Somech (2004), examining the effect of empowering teachers on job commitment, professional commitment and OCB in schools, concluded that teachers' OCB was moderate and empowering teachers, job commitment and the professional commitment were significantly correlated. Gautam, Van Dick, Upadhyay, \& Davis (2005), investigating the relationship between OCB and the OC in Nepal, indicated that there was a significant positive relationship between OCB and OC.

In another study, Alotaibi (2005) investigated the effect of job satisfaction, justice perception and OC on OCB and concluded that only OC was associated with OCB. Cohen (2006) examined the relationship between OC and OCB and found a positive relationship between OC and OCB. Goudarzi \& Chegini (2009) emphasized the most important aspect of citizenship, i.e. organizational loyalty, in which members of an organization work above their average professional requirements, being closely linked with OC. Skarlicki (2001), exploring the intercultural perception of organizational perceptions, concluded that organizational justice could predict organizational outcomes which was positively correlated with employees' loyalty, commitment and behaviors beyond the role.

Findings of Tavakoli, Abedi, \& Salehnia (2009), investigating the effect of OCB training on OC, indicated 
that OCB training increased OC. Ramin Mehr et al. (2009), examining the relationship between perceptions of organizational justice and OCB (Iranian National Oil Products Distribution Company, Tehran staff), showed that the relationship between perceptions of organizational justice and OCB was significant. Findings of Jafari, Sadeghi, \& Khodayari Zarnaq (2011) on the relationship between OCB and OC in Martyr Hashemi Nejad hospital in Tehran suggested that there was a significant relationship between the dimensions of OC and OCB, and among the components of OCB, sportsmanship and civic virtue had a significant positive relationship with OC; however, no significant relationship was observed between the dimensions of the respect, civility, altruism and conscientiousness and OC.

Hamdi \& Moradi Dulama (2011), investigating the relationship between OCB and OC among employees of Azerbaijan Fard Company in Urmia, found a significant relationship between OCB and OC. Hassani \& Jodat Kordlar (2012) investigated the relationship between perceptions of organizational justice, job satisfaction and OCB in Urmia, and found that there was a positive correlation between perception of organizational justice and OCB. Parnian (1999), exploring employees' perceptions according to Adams' equity theory, its development and relationship with OC, found that employees' perceptions of organizational conditions, salary, work and working environment, organizational respect and attention and procedural justice varied, and employees were divided into three categories of negative inequity perception, positive inequity perception and equity perception, and that these types of perception affected OC.

Eskandari (2008) examined the relationship between EP, OC and job attachment among teachers in Arsanjan and found a significant relationship between EP, OC and OCB as well as between the dimensions of EP and OC and job attachment. Results of Hosseini Qadykayi, Mohammadian Saravi, \& Abov (2010), investigating the relationship of EP with OC and job satisfaction among teachers in Savadkouh, indicated a significant relationship between EP, OC and job satisfaction, while the relationship between $\mathrm{OC}$ and job satisfaction was not significant (Figure 1). Based on the above studies and the results of previously conducted research, the conceptual model of the present research was constructed as follows:

\section{Research Questions}

1) Is there any significant relationship between administrators' OCB and its dimensions and EP?

2) Is there any significant relationship between administrators' OCB and its dimensions and OC?

3) Is there a significant relationship between administrators' EP and OC?

4) Are dimensions of OCB able to predict administrators' EP?

5) Are dimensions of OCB able to predict administrators' OC?

\section{Method}

Since the purpose of this study was to investigate the relationship of secondary school administrators' organizational citizenship behavior with organizational commitment and equity perception in Zahedan, the descriptive-correlational method was used. The population included all secondary school administrators in Zahedan in 2013-2014 academic year $(\mathrm{N}=92)$. The Morgan's table represented a sample size of 75 for a population of 92; however, considering the ratio of $15 \%$, the whole population of administrators was selected as the final sample participants. After collecting the data, a number of incomplete questionnaires (14 copies) were excluded from the analysis and data analysis was conducted with 78 (37 male and 41 female) participants.

\begin{tabular}{cccc}
\hline Gender & Male & 37 \\
& & Female & 41 \\
& Education & BA & 58 \\
& & MA and higher & 19 \\
& & $6-10$ years & 38 \\
\hline
\end{tabular}




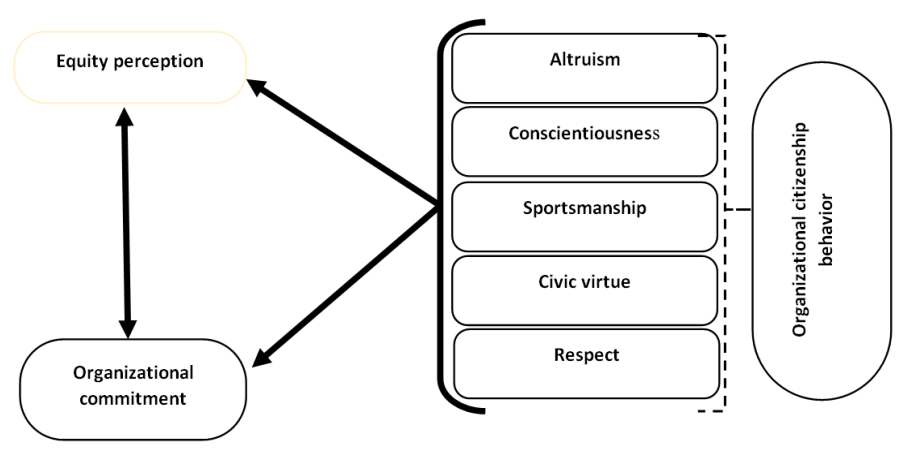

Figure 1. The conceptual model of the relationship between OCB and its dimensions with $\mathrm{OC}$ and EP (by researcher).

\section{Data Collection Tool}

To collect the data related to the variables under study, Podsakoff's Organizational Citizenship Behavior Questionnaire (2000) and Estrone's Equity Perception Inventory (1996) were used. Podsakoff's Organizational Citizenship Behavior Questionnaire has 20 items, assessing managers' organizational citizenship behavior, using a 5 -point Likert type scale ( $5=$ strongly agree, $4=$ agree, $3=\mathrm{I}$ have no idea, $2=$ disagree, $1=$ strongly disagree). Equity Perception Inventory has 21, 5-point Likert type scale items $(5=$ strongly agree, $4=$ agree, $3=\mathrm{I}$ have no idea, 2 = disagree, 1 = strongly disagree) developed by Estrone. To measure organizational commitment, a questionnaire developed by Steers and Porter (1998) including 15 questions was applied. This questionnaire has 7 options $(1=$ strongly disagree, $2=$ somehow disagree, $3=$ slightly disagree, $4=$ neither agree nor disagree, $3=$ slightly agree, $4=$ somehow agree, strongly agree). Questions $1,2,4,5,6,7,8,10,13$, and 14 are scored based on the mentioned points and questions $3,7,9,11,12$, and 15 are reversely scored. The minimum possible score is 15 and the maximum score is 105 . Higher scores indicate an individual's greater commitment to the organization.

\section{Data Collection Instruments}

To measure organizational citizenship behavior, organizational commitment and equity perception, the following questionnaires were used:

1) Podsakoff's (2000) Organizational Citizenship Behavior Inventory including 20 items designed based on a Likert-type scale. It contains 5 dimensions including altruism (items 1 - 4), conscientiousness (items 5 - 8) sportsmanship (item 9 to 12), civic virtue (13 - 16) and tribute (items 17 - 20);

2) Strone's Equity Perception Inventory (1996) including 21 items;

3) Steers and Porter's (1998) Organizational Perception Inventory including 15 items.

The content validity of the questionnaires was checked and their reliability was estimated using Cronbach's alpha coefficient which was $0.93,0.83$ and 0.72 , respectively. Moreover, Cronbach's alpha coefficients of altruism, conscientiousness, sportsmanship, civic virtue, and tribute were calculated which was $0.80,0.73,0.73,0.82$ and 0.71 , respectively.

\section{Data Analysis}

Descriptive data analysis was conducted using mean and standard deviation. Moreover, for inferential data analysis, the Pearson correlation coefficient and stepwise regression analysis were applied. All these statistical data analyses were conducted after entering the obtained data into the SPSS software version 18.

For analyzing the responses related to questions 1, 2, and 3, the Pearson correlation coefficient and for analyzing the responses associated with questions 4 and 5, stepwise regression were used.

\section{Results}

Q1: Is there any significant relationship between administrators' OCB and its dimensions and EP?

Results in Table 1 indicate that the correlation coefficient of OCB with EP is $r=0.25$. Moreover, altruism ( $r$ $=0.24)$ and conscientiousness $(\mathrm{r}=0.26)$ have a significant correlation with equity perception at the $95 \%$ level $(p$ 
$<0.05)$.

Q2: Is there any significant relationship between administrators' OCB and its dimensions and OC?

Results in Table 2 indicate that the correlation coefficient of OCB with OC is $r=0.38$. Moreover, conscientiousness $(\mathrm{r}=0.33)$, sportsmanship $(\mathrm{r}=0.35)$, civic virtue $(\mathrm{r}=0.36)$, and tribute $(\mathrm{r}=0.39)$ have a significant direct relationship with organization commitment at the $95 \%$ level $(p<0.01)$. Therefore, there is a statistically significant positive relationship between OCB and dimensions of conscientiousness, sportsmanship, civic virtue, and tribute and OC.

Q3: Is there a significant relationship between administrators' EP and OC?

Results in Table 3 indicate that the correlation coefficient of EP with OC is $r=-0.28$ which is significant at the $95 \%$ level $(p<0.05)$. Therefore, there is a statistically significant negative relationship between EP and OC. Conscientiousness and tribute can predict EP and conscientiousness, civic virtue and tribute together can predict OC.

Q4: Are dimensions of OCB able to predict administrators' EP?

Table 4 suggests that conscientiousness is a better predictor compared to other dimensions. This variable alone can predict $6.6 \%$ of the variations in EP. The standardized beta coefficient indicates that conscientiousness has a coefficient of 0.26 in the regression equation.

Q5: Are dimensions of OCB able to predict administrators' OC?

Table 5 suggests that tribute is a better predictor compared to other dimensions. This variable alone can predict $15 \%$ of the variations in OC. The standardized beta coefficient indicates that tribute has a coefficient of 0.39 in the regression equation.

\section{Discussion and Conclusion}

The purpose of this study was to examine the relationship of organizational citizenship behavior with organizational commitment and equity perception of secondary school administrators in Zahedan. Regarding the findings, it should be noted that there was a significant positive relationship between OCB and EP of secondary school administrators. Accordingly, it can be stated that with the increase or decrease of OCB, EP will likely increase or decrease respectively. Thus, it can be concluded that individuals with high scores on OCB have a higher perception of equity. This finding is in line with the findings of Ramin Mehr et al. (2009) and Hassani \& Jodat Kordlar (2012).

Since in OCB representations, employees move beyond their defined roles, take the role of supportingtheir colleagues and stand against adversity, this behavior can lead to increased EP. The findings also indicated that there was a significant positive relationship between some dimensions of OCB including altruism and con-

Table 1. Correlations between OCB and its dimension with EP.

\begin{tabular}{ccccccc}
\hline Variables & Organizational citizenship & Altruism & Conscientiousness & Sportsmanship & Civic virtue & Tribute \\
\hline $\mathrm{r}$ & 0.25 & 0.24 & 0.26 & 0.20 & 0.19 & 0.16 \\
$\mathrm{sig}$ & 0.027 & 0.036 & 0.023 & 0.203 & 0.081 & 0.152 \\
\hline
\end{tabular}

Table 2. Correlations between OCB and its dimension with OC.

\begin{tabular}{ccccccc}
\hline Variables & Organizational citizenship & Altruism & Conscientiousness & Sportsmanship & Civic virtue & Tribute \\
\hline $\mathrm{r}$ & 0.38 & 0.22 & 0.33 & 0.35 & 0.36 & 0.39 \\
$\mathrm{sig}$ & 0.000 & 0.057 & 0.003 & 0002 & 0.001 & 0.000 \\
\hline
\end{tabular}

Table 3. Correlations between EP and OC.

\begin{tabular}{cccccc}
\hline Variables & $\mathrm{N}$ & $\mathrm{M}$ & $\mathrm{SD}$ & $\mathrm{r}$ & sig \\
\hline EP & 78 & 88.08 & 7.06 & -0.24 & 0.028 \\
OC & 78 & 80.99 & 11.97 & & \\
\hline
\end{tabular}

Table 4. Summary of the regression model of OCB dimensions to predict EP.

\begin{tabular}{cccccccc}
\hline Step & Variable & $\mathrm{R}$ & $\mathrm{R}^{2}$ & $\mathrm{~F}$ & $\beta$ & $\mathrm{t}$ & $\mathrm{sig}$ \\
\hline 1 & conscientiousness & 0.26 & 0.066 & 5.41 & 0.258 & 5.14 & 0.023 \\
\hline${ }^{*} p<0.05 \mathrm{~N}=78$. & & & & & & &
\end{tabular}


Table 5. Summary of the regression model of OCB dimensions to predict OC.

\begin{tabular}{cccccccc}
\hline Step & Variable & $\mathrm{R}$ & $\mathrm{R}^{2}$ & $\mathrm{~F}$ & $\beta$ & $\mathrm{t}$ & $\mathrm{sig}$ \\
\hline 1 & Tribute & 0.38 & 0.151 & 13.52 & 0.389 & 9.83 & 0.000 \\
\hline
\end{tabular}

${ }^{*} p<0.01 \mathrm{~N}=78$.

scientiousness and EP. Further findings indicated that there was a significant positive correlation between OC and OCB. The findings are consistent with what Parnell \& Crandall (2003), Bogler \& somech (2004), Alotaibi (2005), Gautam, Van Dick, Upadhyay, \& Davis (2005), Cohen (2006), Jafari et al. (2011), Abedi \& Salehnia (2009), Arizi \& Golparvar (1388) and Hamdi \& Dulama (2012) have found. Therefore, it can be concluded that administrators with higher scores on OCB have a stronger sense of loyalty to their organization.

Additionally, the findings suggested that conscientiousness, sportsmanship, civic virtue and tribute had a significant positive correlation with OC. This finding is consistent with Jafari et al.'s (2011) findings indicating the relationship of civic virtue and sportsmanship and $\mathrm{OC}$ as being direct. In addition, a significant negative relationship was observed between EP and OC. This finding was not consistent with the results of Skarlicki (2001), Parnian (1999), Eskandari (2008), and Hosseini Qadykayi et al. (2012) who observed a significant positive correlation between these two variables. The above finding is not anticipated, since OC encompasses the sense of loyalty toward the organization as well as accountability which is closely linked to EP. On the other hand, when all members of an organization who tend to work well feel no discrimination on the organization's side, they will exhibit such behavior. Therefore, if justice governs an organization, employees will feel equity.

The sense of equity provides satisfaction and commitment to organizational responsibilities and goals. Stepwise regression analysis also revealed that among the dimension of $\mathrm{OCB}$, just conscientiousness was able to predict the administrators' EP. It is correlated with EP up to 26\%. Thus, it can be concluded that conscientious administrators who take public interests into account continue working in the worst conditions, e.g. illness or disability. This represents their high conscientiousness which can lead to increased EP. Finally, the results of stepwise regression indicated that only tribute could predict the administrators' OC. Thus, high levels of respect and tribute by officials toward administrators are associated with higher OC.

The limitations of the present study were questionnaire limitations, lack of research background on EP and generalization problems. Thus, researchers recommend to conduct similar research studies on different statistical populations and to apply causal-comparative methods to find possible relationships between variables such as EP and organizational culture, EP and organizational performance or organizational climate and the like.

\section{References}

Alotaibi, G. A. (2005). Antecedents of Organizational Citizenship Behavior: A Study of Public Personnel in Kuwit. Public Personnel Management, 30, 350-363.

Appelbaum, S., Bartolomucci, N., Beaumier, E., Boulanger, J., Corrigan, R., Dore, I., Girard, C., \& Serroni, C. (2004). Organizational Citizenship Behavior: A Case Study of Culture, Leadership and Trust. Management Decision, 42, 13-40. http://dx.doi.org/10.1108/00251740410504412

Awwad, M. S., \& Agti, D. A. M. (2011). The Impact of Internal Marketing on Commercial Banks' Market Orientation. International Journal of Bank Marketing, 29, 308-332. http://dx.doi.org/10.1108/02652321111145943

Ayoubi Rad, M. (2009). OCB Relationship with Emotional Intelligence of Staff of Tehran Municipality Region 4. MA Thesis, Tehran: Science and Research, Islamic Azad University.

Baker, T. L., Hunt, T. G., \& Andrews, M. C. (2006). Promoting Ethical Behavior and Organizational Citizenship Behaviors: The Influence of Corporate Ethical Values. Journal of Business Research, 59, 840-857. http://dx.doi.org/10.1016/j.jbusres.2006.02.004

Belcourt, M., Bohlander, G., \& Snell, S. (2008). Managing Human Resources (5th Canadian ed.). Torento: Thomson-Nelson.

Bjork, I. T., Samdal, G. B., Hansen, B. S., Torstad, S., \& Hamilton, G. A. (2007). Job Satisfaction in a Norwegian Population of Nurses: A Questionnaire Survey. International Journal of Nursing Studies, 44, 747-757. http://dx.doi.org/10.1016/j.ijnurstu.2006.01.002

Bogler, R., \& Somech, A. (2004). Influence of Teacher Empowerment on Teachers Organizational Commitment, Professional Commitment and Organizational Citizenship Behavior in Schools. Teaching and Teacher Education, 20, $277-289$. http://dx.doi.org/10.1016/j.tate.2004.02.003

Bolino, M. C., \& Turnley, W. H. (2003). Going the Extra Mile: Cultivating and Managing Employee Citizenship Behavior. 
Academy of Management Executive, 17, 60-71. http://dx.doi.org/10.5465/AME.2003.10954754

Castro, C., Armario, E. M., \& Ruiz, D. M. (2004). The Influence of Employee Organizational Citizenship Behavior Customer Loyalty. International Journal of Service Industry Management, 15, 27-53. http://dx.doi.org/10.1108/09564230410523321

Chiu, S., \& Chen, H. (2005). Relationship between Job Characteristics and Organizational Citizenship Behavior. Journal of Social Behavior and Personality, 33, 523-540. http://dx.doi.org/10.2224/sbp.2005.33.6.523

Cohen, A. (2006). The Relationship between Multiple Commitments and Organizational Citizenship Behavior in Arab and Jewish Culture. Journal of Vocational Behavior, 69, 105-118. http://www.elsevier.com/ http://dx.doi.org/10.1016/j.jvb.2005.12.004

Eskandari, N. (2008). Examine the Relationship between Organizational Commitment and Equity Perception among Arsanjan Teachers.

Finkelstein, A., \& Penner, A. (2004). Predicting Organizational Citizenship Behavior: Integrating the Function and Role Identity Approach. Social Behavior and Personality, 32, 383-398. http://dx.doi.org/10.2224/sbp.2004.32.4.383

Gautam, T., Van Dick, R., Wagner, U., Upadhyay, N., \& Davis, A. J. (2005). Organizational Citizenship Behavior and Organizational Commitment in Nepal. Asian Journal of Social Psychology, 11, 305-314. http://www.abs.aston.ac.uk http://dx.doi.org/10.1111/j.1467-839X.2005.00172.x

Goudarzi \& Chegini, M. (2009). The Relationship between Organizational Justice and Organizational Citizenship Behavior. American Journal of Economic and Amines Traction, 2, 171-174.

Hamdi, K., \& Moradi Dulama, S. (2011). Investigating the Relationship between OCB and OC (A Case Study: Among Employees of Azerbaijan Fard Company. Journal of Farasou-e-Management, 5, 33-50.

Hassani, M., \& Jodat Kordlar, L. (2012). The Relationship between Perceived Organizational Justice and Turnover Intentions, Job Satisfaction and Organizational Citizenship Behavior in Medical Staff of Imam Reza hospital in Urmia. Urmia Nursing and Midwifery Faculty, 10, 352-340.

Hossam, M. (2008). An Investigation of the Relationship of Openness to Experience and Organizational Citizenship Behavior. Journal of American Academy of Business, 13, 72-78.

Hosseini Qadykayi, M., Mohammadian Saravi, M., \& Abov, H. (2010). Investigating the Relationship of EP with OC and Job Satisfaction among Teachers in Savadkouh. Journal of Management, 9, 1-10.

Jafari, H., Sadeghi, A., \& Khodayari Zarnaq, R. (2011). The Relationship between OCB and OC in Martyr Hashemi Nejad Hospital in Tehran. Journal of Health Sciences Research, 3.

Korkmaz, T., \& Arpaci, E. (2009). Relationship of Organizational Citizenship Behavior with Emotional Intelligence. Procedia-Social and Behavioral Sciences, 1, 2432-2435. http://www.sciencedirect.com/ http://dx.doi.org/10.1016/j.sbspro.2009.01.428

Parnell, J. A., \& Crandall, W. R. (2003). Propensity for Participative Decision-Making, Job Satisfaction, Organizational Commitment, Organizational Citizenship Behavior and Intentions to Leave among Egyptian Managers. The Multinational Business Review Journal, 11, 45-65. http://dx.doi.org/10.1108/1525383X200300003

Parnian, A. (1999). Assessing Employees' Perceptions Based on Adams' Equity Theory: Understanding the Emergence of the Field of Equality and Its Relationship with Organizational Commitment. MA Thesis, Educational Management, Mashhad: Ferdowsi University of Mashhad.

Ramin Mehr, H., Hadizadeh Moghaddam, A., \& Ahmadi, I. (2009). The Relationship between Perceptions of Organizational Justice and Organizational Citizenship Behavior. Journal of Change Management, 1.

Saatchi, M. (2008). Applied Psychology (Application of Psychology at Work, Organization and Management) (15th ed.). Tehran: Viraiesh Publication.

Skarlicki, D. (2001). Cross Cultural Perspective of Organizational Justice. International Journal of Conflict Management, 12 , 292-300. http://dx.doi.org/10.1108/eb022859

Tavakoli, Z., Abedi, M., \& Salehnia, M. (2009). Investigating the Effect of OCB Training on OC. Journal of Management Perspective, 33, 103-124.

Wang, W., \& Tasi, Y. (2010). The Relationships between Organizational Citizenship Behavior, Job Satisfaction and Turnover intention. Journal of Clinical Nursing, 21, 64-74. 